\title{
Social Media Participation and Local Politics: A Case Study of the Enschede Council in the Netherlands
}

\author{
Robin Effing ${ }^{1}$, Jos van Hillegersberg ${ }^{1}$, and Theo W.C. Huibers ${ }^{2}$ \\ ${ }^{1}$ University of Twente, School of Management and Governance, \\ P.O. Box 217, 7500 AE, Enschede, The Netherlands \\ ${ }^{2}$ University of Twente, Human Media Interaction, Enschede, The Netherlands \\ \{r.effing, j.vanhillegersberg, t.w.c.huibers\} @utwente.nl
}

\begin{abstract}
Social media such as Facebook, Twitter and YouTube are often seen as political game changers. Yet little is known of the effects of social media on local politics. In this paper the Social Media Participation Model (SMPM) is introduced for studying the effects of social media on local political communities. The SMPM aims to explore the relationship between Social Media Participation and Community Participation. The model comprises four constructs: Social Media Choice, Social Media Use, Sense of Community and Community Engagement. The design of the case study was based on the SMPM and took place among the members and parties of the Enschede council, from a large municipality in the Netherlands. Social media participation levels were measured and compared with the Social Media Indicator (SMI). A negative correlation between Social Media Use and Sense of Community has been discovered. However, we could not find a causal effect that explains this correlation. To analyze the effects in more detail, we show directions for further improvement of the model.
\end{abstract}

Keywords: social media, council, politics, participation, web 2.0.

\section{Introduction}

Social media change the game of politics both on a national and local scale. Politicians increasingly use social media such as Facebook, Twitter, Blogs, YouTube and LinkedIn. Recent political events showed that social media influence the rules of political participation today.

During the "Arab spring" in 2011, social media allowed social movements to reach once-unachievable goals eventually leading to the fall of oppressing regimes [1]. In presidential elections, the cases of Barack Obama (US) and Ségolène Royal (France) show that effective social media campaigns can make a difference in politics [2-9]. A US Congress Facebook message increased the voting outcome with 340,000 voters [10].

Yet we know little about which social media strategies contribute to political party communities and which do not. The Twitter campaign from the CDU (Germany), for instance, did not result in high numbers of reach and engagement [11]. 
Furthermore, more research should be carried out to understand how social media affects local politics. Local politicians may think that integrating social media in their political work is easy. However, an effective social media strategy requires more than just creating profiles to have a presence on social media. "Considering the novel culture of social media and the shift in power relations, the internalization of social media expertise within an organization may prove to be a much harder task than expected" [12]. Next to the national elections cases, more attention should be paid to the effects of social media on a local scale as well. Local concerns should be an explicit part of the social media strategy in order to be effective [13-14].

In order to maximize the impact of time and effort spent on social media, members of local councils would like to understand the effects of these tools on their work and political communities. Municipalities and their councils are relatively near to the citizens. Social media can potentially help people to establish and foster authentic relations with each other [13]. However, little is known about the effects of social media participation by politicians on such local political communities. Political party communities are relational communities for a professional cause and are not necessarily territorially bounded [15]. The members of political parties are engaged in their communities because of shared beliefs, goals or interests. Does social media participation by members of the party contribute to a stronger party-community? Or is the opposite true? Some parties make social media participation too much of a goal in itself, without any underlying strategy. Such initiatives seem destined to fail.

The aim of this paper is to investigate social media effects within local politics and to learn from local practices. To achieve our goal, we conducted a case study based on the Social Media Participation Model. This model can be used for exploring causal effects of social media participation on communities. The model is still in an early stage of development. By applying this model as the theoretical lens for a case study we can both validate the model and increase understanding of the effects of social media.

Only few models and methods are aimed at understanding the effects of social media participation. The Unified Theory of Acceptance and Use of Technology (UTAUT) from Venkatesh et al. [16],[17] is known to be used to study social media acceptance. However, this theory, and related ones such as the Technology Acceptance Model (TAM), focus merely on adoption of technology and do not capture the effects of use. Other theoretical frameworks from the field of e-participation, such as the participation ladder from Macintosh [18-21], do help to place social media use against a theoretical background, but are too abstract to investigate effects in detail. Therefore, we designed the Social Media Participation Model (Figure 1), aimed at capturing the effects of Social Media Participation on Community Participation. We conducted a case study within the Enschede council and its members based on this model. The municipality of Enschede is located in the eastern part of the Netherlands and has more than 150,000 citizens.

The remainder of this paper is structured as follows. First, we will introduce the Social Media Participation Model. Second, we will clarify our methodology. Third, we will share results from the case of the local government in Enschede. Finally, we will discuss our observations and we will present our future research agenda. 


\section{Introducing the Social Media Participation Model}

Since models to study the effects of social media within the non-profit sector are still scarce [22], we decided to design the Social Media Participation Model for this purpose. This is a model that is aimed to explore the relationship between Social Media Participation on the one hand and Community Participation on the other hand (Figure 1).

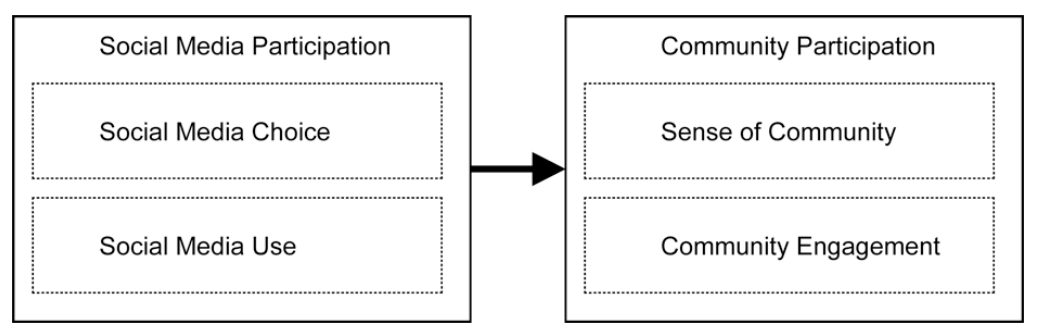

Fig. 1. The Social Media Participation Model

The model takes a high-level approach to a complex reality of social behavior of politicians in both the online and offline world. This means that there can be many (causal) relationships between the included concepts. However, the model concentrates on the assumed causal relation between Social Media Participation by politicians and their Community Participation. We assume that being active on social media affects to some extent the community participation of a politician.

We have three grounds to assume the causality. First, the number of relationships between people tends to increase when people use social network sites, because these sites reveal relationships by making them transparant [23]. As a result, users of social media tend to make more connections with each other, bridging relationship networks [24]. Second, social media do not completely replace offline communication, but augment them, reducing the transaction costs of communication [8],[25]. Third, by taking part in online communities, people become more aware of their connections to others in the community which leads to a stronger bonding to the community in general [24].

After a literature review [22] regarding social media, participation and communities, we decided to derive four more specific constructs from the two concepts in the model.

\subsection{Social Media Choice}

According to Kaplan and Haenlein social media: "is a group of Internet-based applications that build on the ideological and technological foundations of Web 2.0, and that allow the creation and exchange of User Generated Content" [26]. While some politicians start using social media just because they feel they cannot stay behind, others approach them as being part of underlying communication strategies. The choice for certain social media out of the vast amount of available social media 
channels can be dependent of multiple factors but: "Nothing impacts the success of a Social Media effort more than the choice of its purpose" [27]. However, not all communication by social media is appropriate for all communication strategies. Therefore, we have to take the choice and appropriateness of Social Media into account when determining variations in impact on the dependent concept of Community Participation.

After a literature review [22], we selected the theories of Social Presence [28], Media Appropriateness [29],[30] and the Theory of Cognitive and Affective Organizational Communication [31] to warrant Social Media Choice as a construct in the model. All of these theories have shortcomings and should not be applied too rigidly. Nevertheless, they provide us theoretical backgrounds for media choice and communication strategies.

The expected capacity of the social media channels regarding social presence [28] and interaction [29] can influence the choice made by a political party or its members. Social presence is "the degree to which a medium is perceived as conveying the presence of the communicating participants" [28]. While the theory was initially created for telecommunications, it is currently used for social media as well [26]. For different forms of media, differences exist in their capacity to transmit immediate feedback, the interaction capacity [29]. Different communication strategies (for example Exchanging information, Problem solving and Generating Ideas [28], or Contextualization, Affectivity or Control [31]) can require different choices in social media channels (e.g. Twitter for higher level of interaction, YouTube for higher level of social presence). There can be differences in effectiveness of social media use for different purposes. The choice can even be inappropriate for certain communication tasks [26],[30]. Therefore, the strategy and choice determine for a large part the effectiveness of social media for communication goals. Decisions can be made on both the individual and the group level. Sometimes decisons are based on a strategy-plan considering goals, media-channel choice, target audiences and local concerns [12-14].

To explore to what extent politicians use these social media channels, we introduce the next construct of the model: Social Media Use, which is a more quantitative approach.

\subsection{Social Media Use}

We decided to create an instrument, the Social Media Indicator, with metrics based on the participation ladder of Macintosh, including a distinction between e-Enabling and e-Engaging. Macintosh [18-21] created a three-step participation ladder, which can be applied to the Social Media phenomenon from a high-level perspective. The first step on the ladder is e-Enabling. At this step, party members provide access and information to citizens. The second step is e-Engaging. At this step, politicians react, have conversations and interact with citizens based on dialogue. The third step is e-Empowering. At this step, citizens are being invited to take part in the political activities. Politicians start working together with citizens, empowering them with responsibilities, tasks and opportunities to collaborate with the party's community. Previous efforts at trying to empower citizens often failed because of low levels of 
citizen engagement in electronic tools and other technological and democratic shortcomings [32-34]. As Social Media mature, the question remains if social media eventually will lead to the step of e-Empowering. This step is left out of the instrument because it is too difficult to recognize by direct metrics without additional content analysis. In the section of methods, we show our instrument for the measurements. We now continue with the dependent side of the causal model: community participation.

\subsection{Sense of Community}

Community participation has both a tacit and an apparent construct. We address the tacit construct as Sense of Community (SOC), which is: "a feeling that members have of belonging, a feeling that members matter to one another and to the group and a shared faith that members' needs will be met through their commitment to be together" [15]. The Sense of Community can be further divided in four elements [15]: membership, influence, reinforcement and shared emotional connection. The importance of these four elements can vary depending of the type of the community [15]. The theory can be used for studying and comparing different kinds of communities, including political parties and council communities.

\subsection{Community Engagement}

Community engagement is the more apparent construct of community participation. The construct reflects the actual behavior of community members, such as time spent in the community and existing communication ties between members. Since communities are networks of people, the communication ties between politicians can also reflect their actual engagement levels. Christakis and Fowler [2] found out for instance that being connected to each other in a social network influences political party campaigns, voting and co-sponsorship within politics. The social network is more of a group characteristic and makes sense on a higher level: the community level instead of the individual level. Community engagement can be approached from various abstraction levels. In our case we distinguish the individual level and the network level. All four constructs have been explained and we can continue with the methodology that underpinned our case study.

\section{$3 \quad$ Methodology}

The proposed design we present here is based on comparative case study research [7], including both quantitative and qualitative data collection techniques.

We propose a multi-level approach for studies incorporating both the individual level (e.g. the politician) and the group level (e.g. the political faction). The level of inquiry is the individual level. To recognize effects, it is required to conduct more measurements with time intervals in between. 


\subsection{Social Media Choice: Qualitative Interviews}

A selection of members from all parties in the Enschede council were invited for faceto-face semi-structured open interviews. Specific members were selected for interviews in collaboration with the municipality of Enschede. The questions were partly exploratory for getting to know their existing strategy plans. Another part of the interviews was based on the theories of Short et al. [28], Rice [30] and Te'eni [31] and were more directly aimed at understanding their choices for their social media practices. Eight parties accepted the invitation. All interviews were recorded, transcribed and analyzed.

\subsection{Social Media Use: Quantitative Metrics of the Social Media Indicator}

The Social Media Indicator (SMI) has been developed to compare how active community members use social media [22]. This instrument was used in five prior studies, mostly regarding social media use by political candidates and elections outcome. The division between e-Enabling and e-Engagement is based on the e-Participation ladder from Macintosh [18-21]. Due to privacy settings and application programming interface (API) limitations some potentially valuable metrics are excluded from the Social Media Indicator, such as Wall Posts on Facebook. Nevertheless, the SMI provides us with indicative scores. The metrics of the SMI are presented in Table 1 and are based on social media-reach numbers from market researchers ComScore and NewCom. Other social media with high reach can be added for specific studies. The symbol \# means: the number of. Scores can be calculated with the metrics of the SMI to indicate the use of members. We calculated scores for all members of the Enschede council based on the profile information they provided us with an online questionnaire.

Table 1. The Social Media Indicator

\begin{tabular}{lll}
\hline Social media: & e-Enabling: & e-Engagement: \\
\hline Facebook profile & \# friends & \# likes \\
Twitter account & \# tweets & \# following \\
& \# followers & \# retweets* \\
& & \# replies and mentions* \\
YouTube channel & \# videos & \# comments \\
LinkedIn & \# connections & \# recommendations \\
Blog & \# posts & \# replies \\
Total: & Sub score Contribution & Sub score Interaction \\
TOTAL SMI = SUB SCORE CONTRIBUTION + SUB SCORE INTERACTION \\
*of the last 200 Tweets (to limit contribution to total score).
\end{tabular}

\subsection{Sense of Community: Questionnaire with 24 Statements}

To measure the Sense of Community we make use of the SCI-2 instrument [36]. It consists of 24 statements that respondents can respond to on a Likert scale and provides a standardized scoring instruction to evaluate belonging, influence, reinforcement 
and shared emotional connection. We sent this questionnaire to all members of the Enschede council. The total SCI-2 score gives an assessment of the individual sense of community of a member. We asked them for both the overall council community and their own party community as a part of the Enschede council. Because the scale is $24 * 3$ points, there is a maximum of 72 points for the SCI- 2 .

\subsection{Commmunity Engagement: Questionnaire and Social Network Analysis}

In the questionnaire we inquired about the average time members spent per week on their council-affiliation. While such a question does not lead to very reliable information, since members can exaggerate or have different ways of counting, it does help to understand how actively the politicians perceive their own engagement. If there are more reliable ways to obtain the engagement, these should be preferred. Additionally, we created social network diagrams of the primary communication relationships within the community. These network diagrams can be made after asking the member for a top five list of other members of the council, with which they communicate the most. This helps to understand how communication, power and influence within a community are distributed [2].

\subsection{Data Analysis, Statistics and Social Networking Analysis}

We analyzed our four constructs and relationships as follows. For the quantitative constructs we applied regular forms of statistical analysis (means, graphs and Std. Dev.). For the qualitative interviews we took an exploratory approach to capture motivations, and underlying reasons for social media choices. Social networking analysis software, such as Gephi, was used to create network diagrams of the existing ties between members. Furthermore, to discover effects, we applied various statistical methods with SPSS to explore possible relationships between the constructs.

\section{Case Study Results from the Enschede Council}

The municipality of Enschede, located in the eastern part of the Netherlands with more than 150,000 citizens, was interested in how social media affected the work of politicians within their council. In April 2011 the initiative was taken to start this research project. The case study was conducted between June 2011 and March 2013. The 39 members of the Enschede council were elected in March 2010. The members represent nine different parties (political factions).

The design of the case study was based on the Social Media Participation Model. The researchers took the role of observers and did not interfere with any social media planning or helping the candidates. Two measurements were carried out regarding the entire population of the council $(n=39)$. The first measurement (T1) was from November 2011 until April $2012(\mathrm{n}=29$ response 74\%). The second measurement (T2) was from October 2012 until December $2012(n=26$ response 67\%). We will now present results from this study. 


\subsection{Social Media Choice}

Twitter is the preferred social platform of the interviewees of the council. The members believe Twitter can contribute the most towards increasing political participation of citizens. However, members argue the importance of "the physical side of communication ... it is important to keep having conversations" (Interviewee). And, based on their experiences, the members do not think that social media is revolutionary for local politics: "Twitter did not deliver the miracle we hoped for in advance". Only one of the nine political parties prepared a social media strategy. Some parties had a few loosely defined agreements about what they do with social media. Generally, the parties did not approach social media strategically: "we are in the end amateurs, we just do something, in our free time ... we would like social media strategies, but we need external help for that" (Interviewee).

One interviewee, one of the most active social media users of the council, mentioned difficulties with interaction: "during the past months where I have been spokesman on Facebook, I have created links to the documents we discuss so that people can read them and you would like to see interaction as a result, but that does not happen."

\subsection{Social Media Use}

Based on the Social Media Indicator we discovered that $93 \%$ of the members of the Enschede council use social media $(n=28) .93 \%$ of all members use LinkedIn. $82 \%$ uses Twitter. Figure 2 shows a chart of the social media use by all members of the council sorted from high to low (Entire history use until April 2012). The lighter areas in the bars indicate the part of the communication that is interaction (e-Engagement) while the darker areas indicate contribution (e-Enabling). The highest SMI score of a member in this measurement was 19,141 .

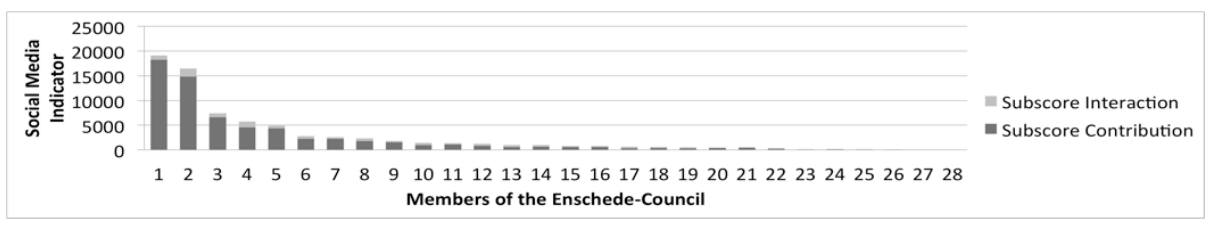

Fig. 2. Social Media Use (Sorted high to low) of members on until April 2012

The second measurement captures a shorter period of time (April - November) and shows increased levels of interaction (e-Engagement) and fewer differences between members in comparison with measurement one in figure 3 . The highest score in the second measurement was 7,598 from the same member as in the first measurement. 


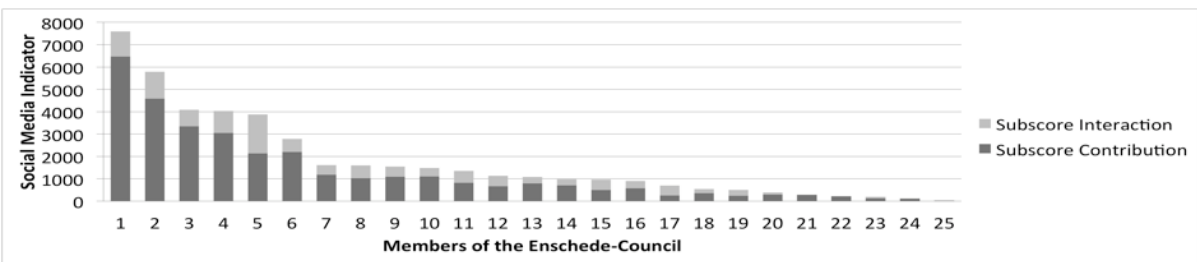

Fig. 3. Social Media Use (Sorted high to low) of members from April 2012 - November 2012

\subsection{Sense of Community}

$96 \%(n=23)$ of the members of the council have a positive score (37-72) for the Sense of Community (SCI-2) within their parties. The second measurement showed an increase of positive scores to $100 \%(n=21)$. A SCI- 2 score above 36 is positive. Values between 0 and 36 in the figure below are negative scores.

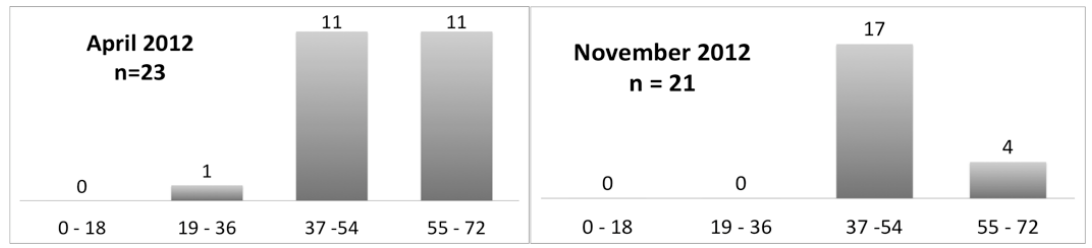

Fig. 4. Measurement of SCI of members in April (left) and November (right) 2012

One of the four factors of the Sense of Community was relatively low for all members, the shared emotional connection. This makes sense since the parties (fractions) are primarily professional communities and offer fewer incentives for emotional bonding.

\subsection{Community Engagement}

The average member of the Enschede council spends 23.8 hour per week $(n=20)$ (Std. Dev. 7,9) on his or her job.
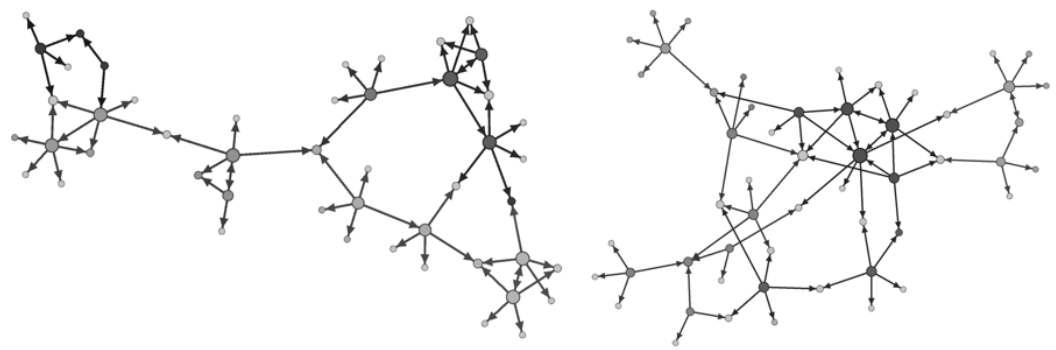

Fig. 5. Social network diagrams April (left) and November (right) 2012 
The social network diagrams in figure 5 show the primary communication ties between members. Every dot is a person and every line a connection. Different shades of grey refer to different parties. In the diagrams above, we can see that the community of the Enschede council is less fragmented in November, indicating a more connected council community.

\subsection{Analysis of Relationships between Concepts}

We found a statistically significant negative correlation between Social Media Use and Sense of Community of members. The Spearman's rho correlation is - .454* (*significant at the 0.05 level, $\mathrm{n}=23$ ). This means that, on average, members who are relatively more active users of social media have relatively lower scores on sense of community. This correlation remained present in the second measurement. We also analyzed effects from SMI on SCI. We checked for variance (with a SPLIT-PLOT ANOVA Repeated Measures) based on splitting the council in two groups. One group of frequent social media users (SMI above 1,000) and a control group. No variance could be proven to signal a causal effect in the Enschede council. Also this analysis showed that the group of frequent social media users had a lower sense of community than the controlgroup of infrequent users.

\section{Discussion and Future Research}

In the case of the Enschede council we see that social media participation by political parties and their members did not make much of a difference for the political game yet. The parties seem to struggle with finding ways to use social media for their own benefits. In Enschede, the parties have not yet professionalized their social media campaigns. Furthermore, strategic approaches considering social media choice, goals, target audience selection and local concerns are still to be defined.

We found a negative correlation (-.454) between social media use and sense of community. However, during the period of the research, the sense of community of members was not influenced by the social media use. This leaves us with a paradox. What does cause the negative correlation? Do members that already have lower levels of sense of community tend to use social media more? This may be the case if there is less bonding with colleagues. Or is it valuable to be connected to others outside the party-fraction, bridging with citizens and organizations? These questions still remain unanswered.

The model can be further refined to recognize more precisely how social media affects political communities such as the Enschede council and its parties. By working with the Social Media Participation model and the specific design of the case-study we encountered four limitations. First, monitoring the use of social media with this instrument has limitations for presenting the real-world behavior of members. Members could have use-scores that actually represent a different background or a large offline network size influences the SMI score. Second, the Sense of Community cannot be separated for online or offline behavior and it can consist of various echelons 
(such as local versus national communities). Third, the decision for members whether or not to participate in social media is sometimes dependent from a higher authority level in the political party, exceeding the communication strategies as provided in our model. Fourth, the SMPM is based on a linear causal view, while in reality the constructs also influence each other in cycles and maybe Community Participation influences the Social Media Participation.

In the near future we will finish measuring two other types of non-profit communities: church-communities and charities. Additionally, we will develop a tool to automatically retrieve SMI scores for social media use. We have also planned to integrate more social media strategy theory in our work. We encourage other scholars to contribute to more refined models and methods to investigate how social media affects local politics and their communities.

Acknowledgements. The case study was initiated in collaboration with the Municipality of Enschede and the broader research project is supported and funded by Saxion University of Applied Sciences, Enschede, The Netherlands.

\section{References}

1. Howard, P.N., Hussain, M.M.: The role of digital media. Journal of Democracy 22, 35-48 (2011)

2. Christakis, N.A., Fowler, J.H.: Connected: The Surprising Power of Our Social Networks and How They Shape Our Lives. Little, Brown and Company (2009)

3. Citron, D.K.: Fulfilling Government 2.0's Promise with Robust Privacy Protections. Arguendo, The George Washington Law Review 78, 822-845 (2010)

4. Greengard, S.: The First Internet President. Comm. of the ACM 52, 16-18 (2009)

5. Lilleker, D.G., Pack, M., Jackson, N.: Political Parties and Web 2. 0: The Liberal Democrat Perspective. Political Studies 30, 105-112 (2010)

6. Montero, M.D.: Political e-mobilisation and participation in the election campaigns of Ségolène Royal (2007) and Barack Obama (2008). Quaderns Del. Cac. 33, 27-34 (2007)

7. Talbot, D.: How Obama Really Did It: The Social-networking Strategy that took an Obscure Senator to the Doors of the White House. Technology Review (2008)

8. Ren, J., Meister, H.-P.: Drawing Lessons from Obama for the European Context. The Internetional Journal of Public Participation 4, 12-30 (2010)

9. Zhang, W., Johnson, T.J., Seltzer, T., Bichard, S.L.: The Revolution Will be Networked. Social Science Computer Review 28, 75-92 (2010)

10. Kiderra, I.: Facebook Boosts Voter Turnout. UCSan Diego News Centre (2012), http://ucsdnews.ucsd.edu/pressreleases/facebook_fuels_the_ friend_vote

11. Jungherr, A.: Online Campaigning in Germany: The CDU Online Campaign for the General Election 2009 in Germany. German Politics 21(3), 317-340 (2012)

12. Munar, A.M.: Destination Management Social Media Strategies and Destination Management. Scandinavian Journal of Hospitality and Tourism 12(2), 101-120, 37-41 (2012)

13. Bottles, K., Sherlock, T.: Who should manage your social media strategy? Physician Executive 37, 68-72 (2011) 
14. Berthon, P.R., Pitt, L.F., Plangger, K., Shapiro, D.: Marketing meets Web 2.0, social media, and creative consumers. Business Horizons 55, 261-271 (2012)

15. McMillan, D.W., Chavis, D.M.: Sense of community: A definition and theory. Journal of Community Psychology 14, 6-23 (1986)

16. Venkatesh, V., Morris, M., Davis, G., Davis, F.: User Acceptance of Information Technology: Toward a Unified View. MIS Quarterly 27, 425-478 (2003)

17. Curtis, L., et al.: Adoption of social media for public relations by nonprofit organizations. Public Relations Review 36, 90-92 (2010)

18. Macintosh, A., Smith, E.: Citizen Participation in Public Affairs. In: Traunmüller, R., Lenk, K. (eds.) EGOV 2002. LNCS, vol. 2456, pp. 256-263. Springer, Heidelberg (2002)

19. Grönlund, Å.: ICT Is Not Participation Is Not Democracy - eParticipation Development Models Revisited. In: ePart 2009, pp. 12-23 (2009)

20. Medaglia, R.: Measuring the diffusion of eParticipation: A survey on Italian local government. Information Polity 12, 265-280 (2007)

21. Sommer, L., Cullen, R.: Participation 2.0: A Case Study of e-Participation. In: 42nd Hawaii International Conference on System Sciences (2009)

22. Effing, R., Van Hillegersberg, J., Huibers, T.W.C.: Measuring the Effects of Social Media Participation on Political Party Communities. In: Reddick, C.G., Aikins, S.K. (eds.) Web 2.0 Technologies and Democratic Governance (2012)

23. Boyd, D.M., Ellison, N.B.: Social Network Sites: Definition, History, and Scholarship. Journal of Computer-Mediated Communication 13, 210-230 (2008)

24. Tomai, M., et al.: Virtual communities in schools as tools to promote social capital with high schools students. Computers \& Education 54, 265-274 (2010)

25. Vergeer, M., Pelzer, B.: Consequences of media and Internet use for offline and online network capital and well-being. A causal model approach. Journal of Computer-Mediated Communication 15, 189-210 (2009)

26. Kaplan, A.M., Haenlein, M.: Users of the world, unite! The challenges and opportunities of Social Media. Business Horizons, 59-68 (2010)

27. Bradley, A., McDonald, M.P.: Social Media Success Is About Purpose. Harvard Business Review Blog (2011), http: / /blogs .hbr .org/cs / 2011/11/

28. Short, J., Williams, E., Christie, B.: Social Psychology of Telecommunications. Wiley, London (1976)

29. Daft, R.L., Lengel, R.H.: Organizational Information Requirements, Media Richness and Structural Design. Management Science 32, 554-571 (1986)

30. Rice, R.E.: Media appropriateness: using social presence theory to compare traditional and new organizational media. Human Communication Research 19, 451-484 (1993)

31. Te'eni, D.: Review: A Cognitive-Affective Model of Organizational Communication for Designing IT. MIS Quarterly 25, 251 (2001)

32. Phang, C.W., Kankanhalli, A.: A Framework of ICT Exploitation for E-Participation Initiatives. Communications of the ACM 51, 128-132 (2008)

33. Roeder, S., Poppenborg, A., Michaelis, S., Märker, O., Salz, S.R.: "Public Budget Dialogue" - An Innovative Approach to E-Participation. In: Böhlen, M.H., Gamper, J., Polasek, W., Wimmer, M.A. (eds.) TCGOV 2005. LNCS (LNAI), vol. 3416, pp. 48-56. Springer, Heidelberg (2005)

34. Stern, E., Gudes, O., Svoray, T.: Web-based and traditional public participation in comprehensive planning. Environment and Planning 36, 1067-1085 (2009)

35. Yin, R.K.: Case Study Research: Design and Methods. Sage Publications (2009)

36. Chavis, D.M., Lee, K.S., Acosta, J.: The Sense of Community (SCI) Revised: The reliability and Validity. In: Community Psychology Conference, Lisboa, vol. 2 (2008) 